Check for updates

Cite this: RSC Adv., 2017, 7, 28548

Received 17th April 2017

Accepted 16th May 2017

DOI: $10.1039 / \mathrm{c} 7 \mathrm{ra0} 4326 \mathrm{k}$

rsc.li/rsc-advances

\section{Facile fabrication of layer-cake-like nano-micro hierarchical structure for high performance Li storage $\uparrow$}

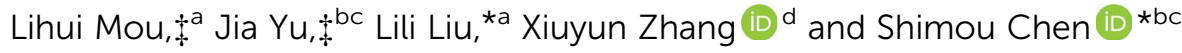

In this work, a cobalt-based nano-micro hierarchical structure is prepared via a facile one-pot hydrothermal process. Showing similar morphology to the traditional Chinese food "thousand-layer-cake", it integrates both the advantages of microscale size and nanoscale design to achieve an efficient balance between $\mathrm{Li}$ storage capacity and tap density. On the one hand, its microscale overall dimensions are beneficial to a high tap density, and prevent excess formation of SEI film. On the other hand, its nanoscale building units and inner voids provide a shortened electron diffusion path and sufficient free space to buffer the volume variation during cycles. After calcination and coating processes, the final $\mathrm{CO}_{3} \mathrm{O}_{4} / \mathrm{C}$ exhibited a capacity as high as $739 \mathrm{~mA} \mathrm{~h} \mathrm{~g}{ }^{-1}$ after 150 cycles, accompanied by excellent long-term cycle stability and rate performance. This layer-cake-like design may provide new ideas for low-cost synthesis of high tap density anode materials for lithium ion batteries.

\section{Introduction}

Driven by continuously increasing demands for high energy density batteries to be applied in electric vehicles and portable electronics, much attention has been paid to developing high capacity electrode materials for next-generation lithium ion batteries (LIBs)..$^{1-3}$ Benefiting from their easily accessible $\mathrm{Li}^{+}$, short diffusion path and large free space, nanostructure electrodes generally show high specific gravimetric capacity and rate capability, and thus are considered as promising candidates. ${ }^{4,5}$ However, other challenges still exist: the nanostructure design usually leads to too-large electrode/electrolyte interfaces, which results in excess formation of a solid electrolyte interface (SEI) layer, ${ }^{6}$ and the electrodes suffer from low tap density caused by the large interparticle space and specific surface area. ${ }^{7}$ This will give rise to capacity fade after long-term cycling, and result in batteries with an undesirable thickness. As major impediments to commercialization, these issues largely offset

${ }^{a}$ Key Laboratory of Cosmetic, China National Light Industry, School of Science, Beijing Technology and Business University, Beijing 100048, China. E-mail: liulili@btbu.edu. cn

${ }^{b}$ Beijing Key Laboratory of Ionic Liquid Clean Process, Key Laboratory of Green Process and Engineering, Institute of Process Engineering, Chinese Academy of Sciences, Beijing 100190, China. E-mail: chenshimou@ipe.ac.cn

'University of Chinese Academy of Sciences, Beijing 100049, China

${ }^{d}$ College of Physics Science and Technology, Yangzhou University, Yangzhou 225002, China

$\dagger$ Electronic supplementary information (ESI) available: SEM images, apparent tap density comparison, TG curve, XPS data. See DOI: 10.1039/c7ra04326k

\$ These authors contributed equally to this work. the advantages of nanostructure electrodes over traditional materials such as graphite anodes.

To solve the problems caused by the intrinsic nature of nanostructure electrodes, fabricating nano-micro hierarchical structures has been proposed as a promising strategy, ${ }^{6-12}$ and several efficient architectures have been reported including pomegranate- ${ }^{6}$ watermelon- ${ }^{8}{ }^{8}$ and plum-pudding-like structures. ${ }^{12}$ These typically show excellent capacity and rate performance benefiting from their nanoscale structure, while maintaining the advantages of SEI formation and packing density afforded by their microscale dimensions. For example, Guo et al. fabricated watermelon-like Si/C hierarchical microspheres by combining spray-drying and CVD processes. ${ }^{8}$ Elsewhere, Guo et al. reported $\mathrm{LiFePO}_{4} /$ carbon hierarchical microtubes via calcination of composite fibers. ${ }^{11}$ Both of the above materials exhibited ideal electrochemical performance. However, traditional synthesis strategies usually either require complex multi-step processes, ${ }^{8}$ or give rise to too-large interspaces and void spaces and thus low tap density. ${ }^{11,13}$ Therefore, constructing a viable nano-micro hierarchical system with targeted properties remains a challenge and is highly dependent on the choice of compositional unit, architecture design and synthetic route.

Recently transition metal oxides (TMOs) have attracted much attention as LIB anode materials, such as $\mathrm{Co}_{3} \mathrm{O}_{4}, \mathrm{FeO}$, $\mathrm{CuO}$, etc. ${ }^{14-16}$ On the one hand, TMOs exhibit much higher theoretical capacities $\left(\sim 800 \mathrm{~mA} \mathrm{~h} \mathrm{~g}^{-1}\right)$ than that of commercial

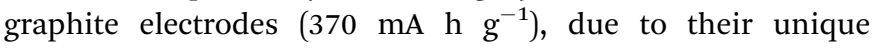
conversion mechanism for Li storage.${ }^{14}$ More importantly, their morphology and composition have superior adjustability via hydrothermal synthesis, to enable construction of the desired 




Scheme 1 Left column: synthetic procedure: (a) fluorine-mediated homogeneous solution system. (b) Layer-cake-like Co(OH)F precursor with nano-micro hierarchical structure prepared via hydrothermal synthesis. (c) $\mathrm{Co}_{3} \mathrm{O}_{4}$ obtained after calcination. (d) $\mathrm{Co}_{3} \mathrm{O}_{4} / \mathrm{C}$ obtained after carbon coating. Right column: comparison of simulated tap density between the layer-cake-like and pompon-like structures.

structure. ${ }^{17,18}$ On the other hand, their nano-micro hierarchical architecture is beneficial for solving several key problems suffered by TMOs, including repeated SEI formation, huge volume variation during $\mathrm{Li}^{+}$insertion/deinsertion and limited diffusion kinetics. ${ }^{4,10,15,19}$

In this work, a layer-cake-like cobalt-based nano-micro hierarchical structure was prepared via a facile one-pot, fluorine-mediated hydrothermal process (Scheme 1). This structure was able to gain an efficient balance between $\mathrm{Li}$ storage capacity and tap density through integrating both the advantages of microscale size and nanoscale design. Concretely, the microsized dimensions gave rise to a high apparent tap density which was about 3 times that of the classical pomponlike structure, and prevented excess formation of SEI film caused by a too-large electrode/electrolyte interface, thus being beneficial for the volumetric energy density and capacity retention. Meanwhile, the nanosized building units and inner void shortened the diffusion pathway for $\mathrm{Li}^{+}$and electrons, and buffered the expansion stress during lithium insertion. Moreover, as a common post-treatment process for anodes, carbon coating further improved the rate capability and cycle stability by enhancing electrical conduction and stabilizing the electrode interface. ${ }^{20,21}$ The final obtained layer-cake-like $\mathrm{Co}_{3} \mathrm{O}_{4} / \mathrm{C}$ structure showed a good Li-storage capacity and excellent cycle stability under a high area mass loading. Benefiting from its unique structure, the layer-cake-like design based on cobalt oxide and corresponding facile synthesis process have great potential in high tap density Li storage.

\section{Experimental}

\section{Preparation methods}

In a typical synthesis process, firstly cobalt nitrate hexahydrate $\left(\mathrm{Co}\left(\mathrm{NO}_{3}\right)_{2} \cdot 6 \mathrm{H}_{2} \mathrm{O}\right)$, urea $\left(\mathrm{CO}\left(\mathrm{NH}_{2}\right)_{2}\right)$ and ammonium fluoride $\left(\mathrm{NH}_{4} \mathrm{~F}\right)$ were dissolved in $40 \mathrm{~mL}$ of deionized water with a molar ratio of $1: 5: 20$, and then the solution was transferred into a 50
$\mathrm{mL}$ Teflon-lined stainless steel autoclave. After being heated at $180^{\circ} \mathrm{C}$ for $6 \mathrm{~h}$, the obtained product was washed with deionized water and ethanol several times followed by drying at $80^{\circ} \mathrm{C}$. The as-prepared layer-cake-like $\mathrm{Co}_{3} \mathrm{O}_{4}$ nano-micro hierarchical structure was obtained after calcination at $550{ }^{\circ} \mathrm{C}$ for $3 \mathrm{~h}$ under air atmosphere, with the colour changing from mauve to black. For the carbon coating treatment, $0.20 \mathrm{~g}$ of as-synthesized $\mathrm{Co}_{3} \mathrm{O}_{4}$ was dispersed in $35 \mathrm{~mL}$ of $1.0 \mathrm{M}$ glucose solution by ultrasonication. Subsequently the suspension was transferred into the autoclave and heated at $180{ }^{\circ} \mathrm{C}$ for $3 \mathrm{~h}$. After washing and drying, the resulting powder was carbonized at $500{ }^{\circ} \mathrm{C}$ for $3 \mathrm{~h}$ under nitrogen atmosphere to obtain the $\mathrm{Co}_{3} \mathrm{O}_{4} / \mathrm{C}$ composite.

As a comparison sample for tap density, a Co-based radial pompon-like structure was prepared using a hydrothermal system containing the same starting materials (cobalt nitrate hexahydrate, urea and ammonium fluoride) but at a molar ratio of $2: 5: 2$. The reaction conditions were equivalent to those for the layer-cake-like structure.

\section{Structural and compositional characterizations}

Scanning electron microscopy (SEM) observation was performed on an SU8020 microscope (Hitachi, Japan) operated at $5.0 \mathrm{kV}$. Transmission electron microscopy (TEM) observation was performed with a JEM-2100F microscope (JEOL, Japan) operated at $200 \mathrm{kV}$. X-ray diffraction (XRD) patterns were recorded using the SmartLab $9 \mathrm{~kW}$ X-ray diffractometer (Rigaku, Japan) at a $2 \theta$ range between $15^{\circ}$ and $70^{\circ}$. X-ray photoelectron spectroscopy (XPS) data were obtained using the ESCALAB 250Xi (Thermo Fisher Scientific, U.S.A.). Thermogravimetric (TG) analysis was performed using the DTG-60H (Shimadzu, Japan) under air atmosphere at a heating rate of $5{ }^{\circ} \mathrm{C} \mathrm{min}^{-1}$. Energy dispersive spectroscopy (EDS) elemental mapping was performed using the X-Max ${ }^{\mathrm{N}}$ (Oxford, U.K.) attached to the SU8020 operated at $20.0 \mathrm{kV}$. 


\section{Electrochemical measurements}

Electrochemical measurements were performed at room temperature using coin-type half-cells. Active material, Super P and polyvinylidene fluoride (PVDF) were mixed with a weight ratio of $80: 10: 10$, followed by being pasted onto copper foil and dried at $80^{\circ} \mathrm{C}$. The mass of active material was measured as the weight difference between the electrode piece and an equivalent piece of bare copper foil, revealing a high average mass loading level of $4.5 \mathrm{mg}$ per piece. Lithium foil was used as the counter electrode, and a Celgard 2400 membrane was used to separate the working electrode and counter electrode. The electrolyte was $1 \mathrm{~mol} \mathrm{~L}^{-1}$ of $\mathrm{LiPF}_{6}$ in an EC/DEC/DMC mixture ( $1: 1: 1$ in weight). To recycle the coin cells, they were discharged to $0.01 \mathrm{~V}\left(v s . \mathrm{Li} / \mathrm{Li}^{+}\right)$and recharged to $3.0 \mathrm{~V}\left(v s . \mathrm{Li} / \mathrm{Li}^{+}\right)$on the Neware battery testing system with various current densities. Cyclic voltammetry (CV) data were recorded on the Autolab (PGSTAT302N) electrochemical workstation, with a scanning rate of $0.1 \mathrm{mV} \mathrm{s}^{-1}$ and a voltage range of $0.01-3.0 \mathrm{~V}$ ( $v s . \mathrm{Li} / \mathrm{Li}^{+}$). Electrochemical impedance spectroscopy (EIS) measurements were carried out on the ACM Gill-AC-4 electrochemical station. After the cycle test, the electrode was washed using electrolyte to observe the morphology.

\section{Results and discussion}

\section{Synthetic procedure and mechanism}

The synthetic procedure and proposed mechanism were as follows. As a prerequisite to formation of a uniform layer-cake structure in the homogeneous hydrothermal system, the fluorine-mediation effect played a significant role (Scheme 1a). ${ }^{22,23}$ During the initial stage, the cobaltous ions $\left(\mathrm{Co}^{2+}\right)$ firstly combined with the fluorine ions $\left(\mathrm{F}^{-}\right)$to form the $\mathrm{CoF}^{+}$complex (eqn (1)). ${ }^{23}$ As the solution temperature increased, the hydrolysis of urea $\left(\mathrm{CO}\left(\mathrm{NH}_{2}\right)_{2}\right)$, which served as a slow-release $\mathrm{pH}$ adjusting agent, was accelerated to generate excess hydroxyl anions $\left(\mathrm{OH}^{-}\right)$(eqn (2)). ${ }^{24}$ Subsequently $\mathrm{CoF}^{+}$combined with the $\mathrm{OH}^{-}$to precipitate into the cobaltous hydroxide fluoride $\mathrm{Co}(\mathrm{OH}) \mathrm{F}$ precursor (eqn (3)), which exhibited a microsized layer-cake-shaped morphology consisting of nanosized sheets (Scheme 1b). The relevant chemical reactions were as follows.

$$
\begin{gathered}
\mathrm{Co}^{2+}+\mathrm{F}^{-} \rightarrow \mathrm{CoF}^{+} \\
\mathrm{CO}\left(\mathrm{NH}_{2}\right)_{2}+3 \mathrm{H}_{2} \mathrm{O} \rightarrow 2 \mathrm{NH}_{4}^{+}+2 \mathrm{OH}^{-}+\mathrm{CO}_{2} \\
\mathrm{CoF}^{+}+\mathrm{OH}^{-} \rightarrow \mathrm{Co}(\mathrm{OH}) \mathrm{F} \downarrow
\end{gathered}
$$

During this hydrothermal stage, the cobalt-based precursor was nucleated and grew. It is worth noting that the initial molar ratio of $\mathrm{F}^{-}$to $\mathrm{Co}^{2+}$ in the hydrothermal system influenced the precursor morphology to a large extent. When the $\mathrm{F}^{-} / \mathrm{Co}^{2+}$ ratio was decreased from 20 to 1 , the precursor was transformed from a layer-cake-shape to a radial pompon-shape. Different morphologies resulted from different precursor compositions, which will be discussed in the following characterization.

After simple calcination, the $\mathrm{Co}(\mathrm{OH}) \mathrm{F}$ precursor was converted into $\mathrm{Co}_{3} \mathrm{O}_{4}$ (eqn (4)). Before testing its electrochemical properties, it was further coated with amorphous carbon, to form a $\mathrm{Co}_{3} \mathrm{O}_{4} / \mathrm{C}$ composite. Glucose was selected as the carbon source, since it is low-cost and can prevent the chaotic coalescence or aggregation of $\mathrm{Co}_{3} \mathrm{O}_{4} / \mathrm{C}$ by favouring particle separation. ${ }^{25,26}$ The relevant chemical reaction was as follows.

$$
6 \mathrm{Co}(\mathrm{OH}) \mathrm{F}+\mathrm{O}_{2} \rightarrow 2 \mathrm{Co}_{3} \mathrm{O}_{4}+6 \mathrm{HF}
$$

\section{Morphology characterization}

The morphologies of the precursor and products at various stages were observed by SEM. As shown in Fig. 1a, after the hydrothermal process, uniform round-cake-shaped precursors were obtained, which exhibited diameters of about 7-10 $\mu \mathrm{m}$ and thicknesses of 1.5-3 $\mu \mathrm{m}$. In high-resolution observation, with its relatively smooth surface and coarse lateral sides, the multiplelayer morphology resembled the traditional Chinese food "thousand-layer-cake". It consisted of sheet-shaped units whose thickness was as low as tens of nanometers, proving the successful fabrication of a nano-micro hierarchical structure. (Fig. 1b and S1 (ESI) $\dagger$ ). The nanosheet building units and intersheet void spaces provided easier and greater access to $\mathrm{Li}^{+}$ and shortened the transport pathway, while efficiently buffering the volume expansion during $\mathrm{Li}^{+}$insertion. The calcined product showed similar morphologies to the precursor, accompanied by plentiful nanopores on the surface. The formation of pores mainly resulted from the release of gas during calcination, and further enhanced the $\mathrm{Li}$ storage performance (Fig. 1c and S2 $\dagger$ ). ${ }^{27,28}$ After carbon coating treatment, the final $\mathrm{Co}_{3} \mathrm{O}_{4} / \mathrm{C}$ composite product maintained a consistent layer-cake-like structure, except for a slightly coarser surface (Fig. 1d and S3†).

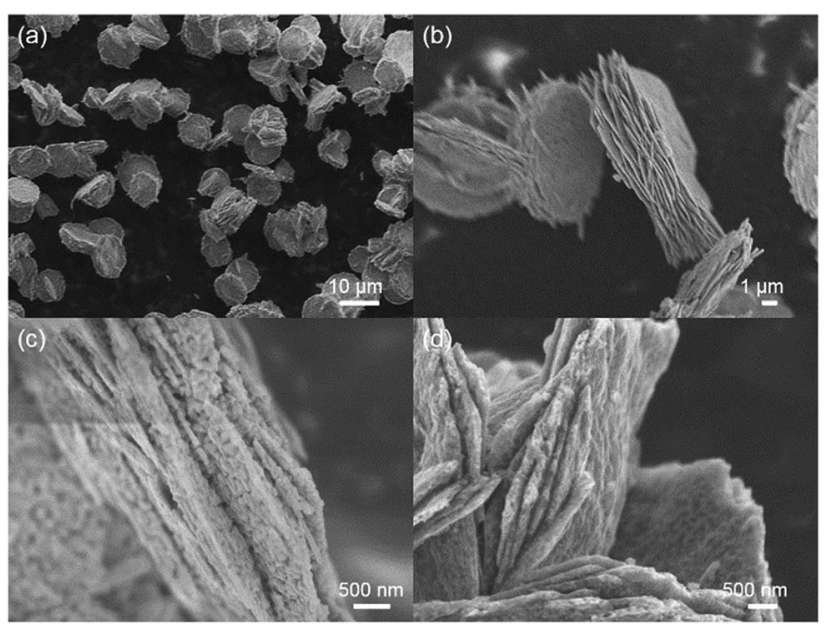

Fig. 1 (a) Overall morphology of $\mathrm{Co}(\mathrm{OH}) \mathrm{F}$ precursors obtained after hydrothermal synthesis, showing diameters of 7-10 $\mu \mathrm{m}$ and thicknesses of 1.5-3 $\mu \mathrm{m}$. (b) High-resolution observation of the layer-cakelike nano-micro hierarchical structure, which consisted of sheetshaped units with a thickness of tens of nanometers. (c) Obtained $\mathrm{CO}_{3} \mathrm{O}_{4}$ after calcination, with plentiful nanopores on the surface. (d) Obtained final product $\mathrm{CO}_{3} \mathrm{O}_{4} / \mathrm{C}$ after carbon coating, maintaining a consistent layer-cake-like structure. 


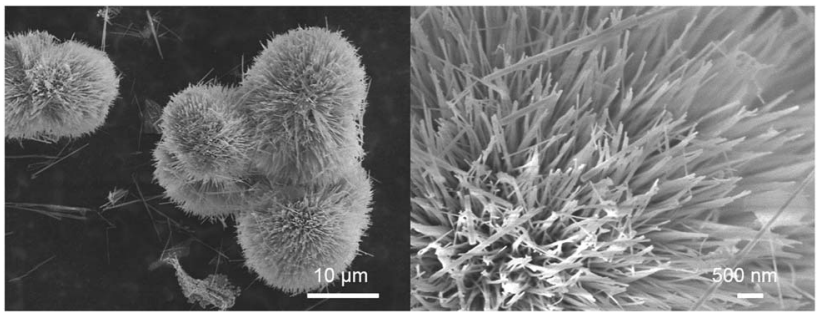

Fig. 2 Morphologies of pompon-like precursor obtained from the hydrothermal system with low $\mathrm{F}^{-} / \mathrm{Co}^{2+}$ ratio, exhibiting average overall dimensions of about $10 \mu \mathrm{m}$ and radial nanowires (basic structural components) of 40-60 nm diameter.

The above-mentioned layer-cake-like structure was obtained in a highly fluorine-enriched system $\left(\mathrm{F}^{-} / \mathrm{Co}^{2+}\right.$ ratio of 20$)$, however, the obtained precursor morphology varied markedly when the fluorine level was changed. Concretely, traditional pompon-like precursors were obtained when the initial $\mathrm{F}^{-} / \mathrm{Co}^{2+}$ ratio was decreased greatly to 1 . They exhibited overall dimensions of about $10 \mu \mathrm{m}$, consisting of nanowires of diameter 40$60 \mathrm{~nm}$ which radially fanned out from the core (Fig. 2). The pompon-structure has been widely studied for LIB anodes based on TMOs, and generally achieves considerable Li storage capacities. ${ }^{\mathbf{2 9 , 3 0}}$ However, the radial arrangement of nanowires (the basic structural components) inevitably leads to loose

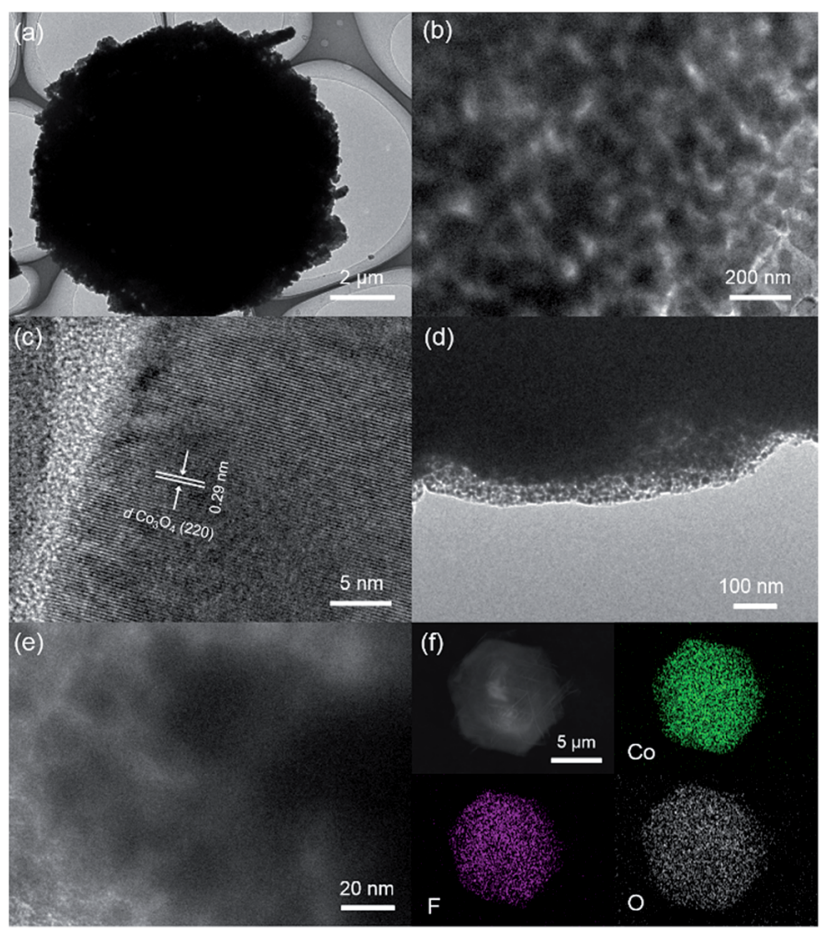

Fig. 3 ( $a$ and b) TEM images of layer-cake-like $\mathrm{CO}_{3} \mathrm{O}_{4}$, exhibiting porous structure consisting of nanoscale grains and voids. (c) Highresolution observation for $\mathrm{CO}_{3} \mathrm{O}_{4}$, showing a dominant (220) lattice plane. ( $d$ and e) TEM images of $\mathrm{CO}_{3} \mathrm{O}_{4} / \mathrm{C}$, exhibiting a uniform carbon coating layer and maintaining a porous structure. (f) EDS element mapping of the layer-cake-like $\mathrm{Co}(\mathrm{OH}) \mathrm{F}$ precursor, confirming the existence of $\mathrm{Co}$ and $\mathrm{F}$. packing and thus low tap density. As shown in Fig. S4, $\dagger$ with the same precursor mass (300 mg), the layer-cake-structure occupied only about one third the volume of the pompon-structure, indicating the high tap density characteristic of the layer-cakelike design. In fact, its apparent tap density was comparable with the commercial graphite material. The architectural mechanism for the difference in packing density between the two structures is illustrated in Scheme 1. The high tap density efficiently enhanced the special volumetric capacity of the electrode, which was beneficial to improving the energy density of the battery system as a whole, showing great potential in practical applications.

The layer-cake-like nano-micro hierarchical structure was further observed by TEM. For the calcined product $\mathrm{Co}_{3} \mathrm{O}_{4}$, Fig. 3a clearly demonstrates the round-cake structure of the final product $\mathrm{Co}_{3} \mathrm{O}_{4} / \mathrm{C}$, with microscale dimensions, which is consistent with the SEM images. As shown in Fig. 3b, grains and voids with sizes of tens of nanometers were observed. This porous nature resulted from the precursor growth process and gas release during calcination, and the pores provided better access and shortened pathways for $\mathrm{Li}^{+}$and electrons. ${ }^{27,28}$ In the high-resolution image, the dominant interplanar spacing of $0.29 \mathrm{~nm}$ belonged to the $\mathrm{Co}_{3} \mathrm{O}_{4}$ (220) lattice planes (Fig. 3c). ${ }^{30} \mathrm{In}$ the final product $\mathrm{Co}_{3} \mathrm{O}_{4} / \mathrm{C}$, a uniform carbon layer was coated on the surface of the $\mathrm{Co}_{3} \mathrm{O}_{4}$ particles, being favorable to the electrode interface stability and allowing extra interfacial lithium storage (Fig. 3d). ${ }^{31}$ And the porous structure was still evident (Fig. 3e). It was clear that the calcination and coating procedure caused no noticeable change in the overall morphology. ${ }^{32}$

\section{Compositional characterization}

To estimate the appropriate calcination treatment temperature for the precursor, the thermal behaviour of $\mathrm{Co}(\mathrm{OH}) \mathrm{F}$ was studied by TG analysis. Fig. 4a shows the TG curve under air with a temperature ramp of $5{ }^{\circ} \mathrm{C} \mathrm{min}^{-1}$, in which the curve is monotonic and the most prominent weight loss took place above $350{ }^{\circ} \mathrm{C}$. The final weight loss, reached at $550{ }^{\circ} \mathrm{C}$, is about $17 \%$, which is slightly larger than the theoretical value for decomposition of $\mathrm{Co}(\mathrm{OH}) \mathrm{F}$ into $\mathrm{Co}_{3} \mathrm{O}_{4}$ under air atmosphere, due to existence of crystalline water in the initial precursor. Similarly, the carbon content in the $\mathrm{Co}_{3} \mathrm{O}_{4} / \mathrm{C}$ final product was estimated to be about $16 \%$ by weight (Fig. $\mathrm{S} 5 \dagger$ ). In addition, the EDS element mapping of the precursor clearly evidenced its chemical composition through indicating the existence of $\mathrm{Co}, \mathrm{O}$ and $\mathrm{F}$ (Fig. 3f).

The crystalline structures were further investigated by XRD to verify the successful fabrication of the final product. As shown in Fig. $4 \mathrm{~b}$, the diffraction peaks from $20.9^{\circ}$ to $61.6^{\circ}$ were all in good agreement with the (110), (310), (201), (400), (111), (211), (410), (311), (221), (420), (511) and (601) faces of orthorhombic $\mathrm{Co}(\mathrm{OH}) \mathrm{F}$ (JCPDS card no. 50-0827), confirming the precursor composition. ${ }^{24}$ For the final product, eight obvious diffraction peaks could be assigned to the (111), (220), (311), (222), (400), (422), (511) and (440) planes of cubic $\mathrm{Co}_{3} \mathrm{O}_{4}$ (JCPDS card no. 42-1467) (Fig. 4d). ${ }^{33}$ This was consistent with the above TG result and the proposed mechanism of precursor 



Fig. 4 (a) TG curve of $\mathrm{Co}(\mathrm{OH}) \mathrm{F}$ precursor. XRD patterns of (b) $\mathrm{Co}(\mathrm{OH}) \mathrm{F}$ precursor, (c) $\mathrm{Co}\left(\mathrm{CO}_{3}\right)_{0.5}(\mathrm{OH}) \cdot 0.11 \mathrm{H}_{2} \mathrm{O}$ precursor and (d) $\mathrm{CO}_{3} \mathrm{O}_{4} / \mathrm{C}$ final product.

decomposition. There were no noticeable peaks with $2 \theta$ values near $26^{\circ}$, indicating that the carbon coating layer was amorphous. $^{25,26}$ Compared with the precursor, the sharper peaks of the final product indicated high crystallinity and relatively large crystallite size after calcination. ${ }^{34}$ Moreover, the XRD pattern of the pompon-like precursor obtained from the low-fluorine hydrothermal system was consistent with orthorhombic $\mathrm{Co}\left(\mathrm{CO}_{3}\right)_{0.5}(\mathrm{OH}) \cdot 0.11 \mathrm{H}_{2} \mathrm{O}$ (JCPDS card no. 48-0083), exhibiting a chemical composition which totally differed from the layercake-structure (Fig. 4c). ${ }^{35}$

In addition, further information on the composition of the precursor and final product was obtained via XPS. Fig. 5a shows the full-survey XPS spectrum of the $\mathrm{Co}(\mathrm{OH}) \mathrm{F}$ precursor, in which sharp peaks assigned to O1s, F1s and Co2p were observed. Concerning the representative Co2p state, the peak at
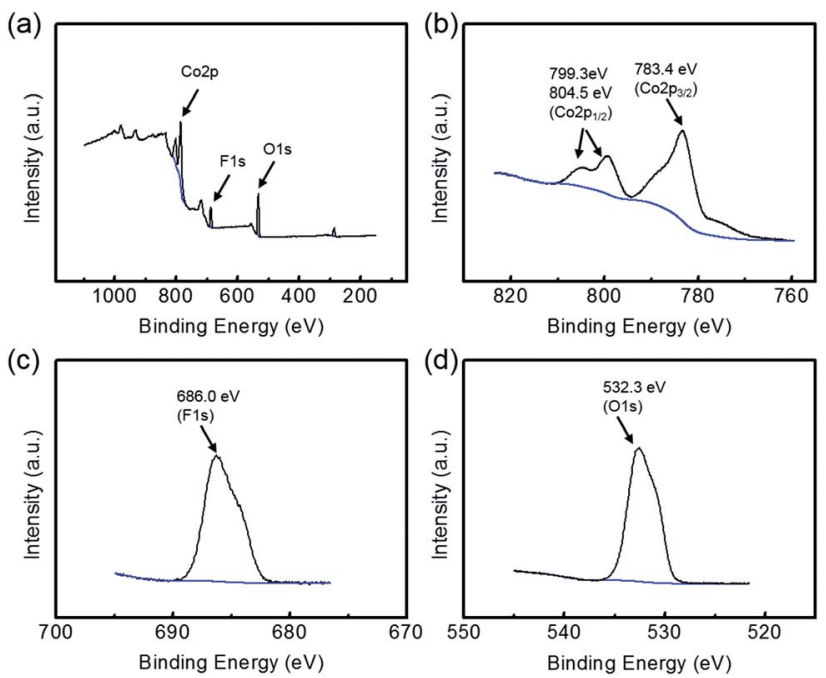

Fig. 5 (a) Full-survey, (b) Co2p, (c) F1s and (d) O1s XPS characterizations of the precursor, further evidencing its chemical composition.
$783.4 \mathrm{eV}$ corresponded to the $\mathrm{Co} 2 \mathrm{p}_{3 / 2}$ state of $\mathrm{Co}(\mathrm{OH}) \mathrm{F}$, while the two peaks of the Co2 $\mathrm{p}_{1 / 2}$ state were located at higher binding energies (around 799.3 and $804.5 \mathrm{eV}$ ) (Fig. 5b). ${ }^{36,37}$ Concerning the F1s state, the peak at $686.0 \mathrm{eV}$ was assigned to the lattice fluorine of $\mathrm{Co}(\mathrm{OH}) \mathrm{F}$ (Fig. $5 \mathrm{c}$ ). ${ }^{22}$ The prominent O1s peak located at $532.3 \mathrm{eV}$ could be attributed to the lattice oxygen of $\mathrm{Co}(\mathrm{OH}) \mathrm{F}$ (Fig. 5d). ${ }^{36}$ For the product $\mathrm{Co}_{3} \mathrm{O}_{4} / \mathrm{C}$, the Co2p spectrum principally contained two major peaks located at binding energies of 781.3 and $796.3 \mathrm{eV}$, which corresponded to the Co2 $\mathrm{p}_{3 / 2}$ and $\mathrm{Co} 2 \mathrm{p}_{1 / 2}$ states respectively (Fig. S6a $\dagger$ ). ${ }^{30}$ Meanwhile, the main O1s peak located at $530.9 \mathrm{eV}$ was assigned to the $\mathrm{O}-\mathrm{Co}$ bond in $\mathrm{Co}_{3} \mathrm{O}_{4}$ (Fig. $\left.\mathrm{S} 6 \mathrm{~b} \dagger\right)^{29}$

\section{Lithium storage performance}

The lithium storage performance of the $\mathrm{Co}_{3} \mathrm{O}_{4} / \mathrm{C}$ nano-micro hierarchical structure as an LIB anode was evaluated using a two-electrode cell, where $\mathrm{Co}_{3} \mathrm{O}_{4} / \mathrm{C}$ and lithium metal served as the working electrode and counter electrode respectively. The conversion reaction mechanism could be described as follows: $\mathrm{Co}_{3} \mathrm{O}_{4}+8 \mathrm{Li}^{+}+8 \mathrm{e}^{-} \leftrightarrow 3 \mathrm{Co}+4 \mathrm{Li}_{2} \mathrm{O} .^{14}$

As shown in Fig. 6a, with a current density of $100 \mathrm{~mA} \mathrm{~g}^{-1}$ and a voltage range of $0.01-3.0 \mathrm{~V}$, the discharge voltage $v s$. capacity curve of the first cycle exhibited a plateau starting around $1.2 \mathrm{~V}$ followed by a downward sloping, which were ascribed to the $\mathrm{Li}$ storage in $\mathrm{Co}_{3} \mathrm{O}_{4}$ and the formation of an SEI film due to interaction with the electrolyte, respectively. ${ }^{33,38}$ In subsequent cycles, the plateau shifted to higher voltage and became less well-defined, while the curves became stable. ${ }^{39}$ It was observed that the initial discharge capacity was $745 \mathrm{~mA} \mathrm{~h} \mathrm{~g}{ }^{-1}$, which would be close to the theoretical capacity of $\mathrm{Co}_{3} \mathrm{O}_{4}(890 \mathrm{~mA} \mathrm{~h}$ $\mathrm{g}^{-1}$ ) if the coating layer weight was further excluded. Besides intrinsic Li storage, the high discharge capacity was partially attributed to the extra interfacial Li storage and the consumption of $\mathrm{Li}^{+}$due to SEI formation. ${ }^{31,40}$ Meanwhile, the charge capacity for the first cycle was $575 \mathrm{~mA} \mathrm{~h}^{-1}$, accompanied by an initial coulombic efficiency of nearly $80 \%$. This is a relatively high efficiency compared with conventional conversion-type anodes, and is attributed to the microscale overall dimensions, which prevent the formation of a too-large interface, and to the carbon coating layer. ${ }^{\mathbf{2 0 , 4 1}}$ The irreversible capacity was mainly due to the incomplete decomposition of the SEI layer, and a possible kinetic limit to $\mathrm{Li}^{+}$extraction. ${ }^{42,43}$

Fig. 6b shows the cycle performance of $\mathrm{Co}_{3} \mathrm{O}_{4} / \mathrm{C}$ at a current density of $100 \mathrm{~mA} \mathrm{~g}^{-1}$. It is found that the reversible capacities show an upward trend during the initial cycles, and reach a maximum discharge capacity of $739 \mathrm{~mA} \mathrm{~h} \mathrm{~g}^{-1}$ after 150 cycles. Meanwhile, the coulombic efficiency is maintained above $98 \%$ after several cycles, indicating the excellent Li storage capacity and superior cycling stability of the layer-cake-like $\mathrm{Co}_{3} \mathrm{O}_{4} / \mathrm{C}$. When compared with the pompon-like structure of $\mathrm{Co}_{3} \mathrm{O}_{4}$ prepared in our previous work, the layer-cake-like structure showed obvious advantages in long-term capacity retention and initial coulombic efficiency, mainly owing to the carbon coating layer, and the more compact and stable framework. However, the pompon-like $\mathrm{Co}_{3} \mathrm{O}_{4}$ showed a higher specific capacity in the initial phase of cycling. ${ }^{30}$ Furthermore, when the current density 
(a)

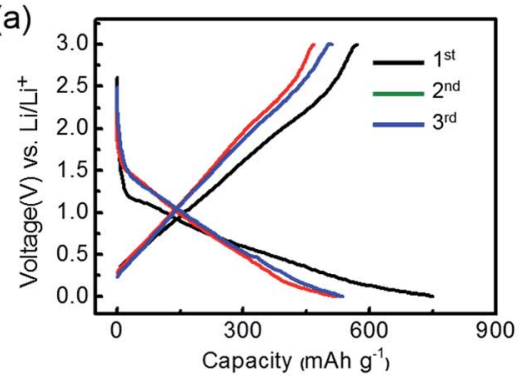

(d)

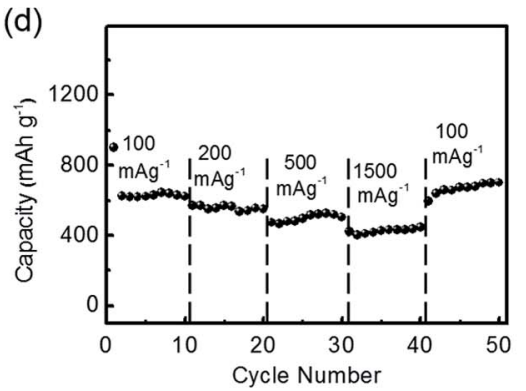

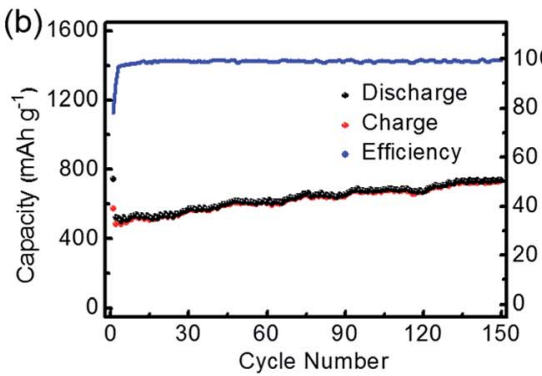

(e)

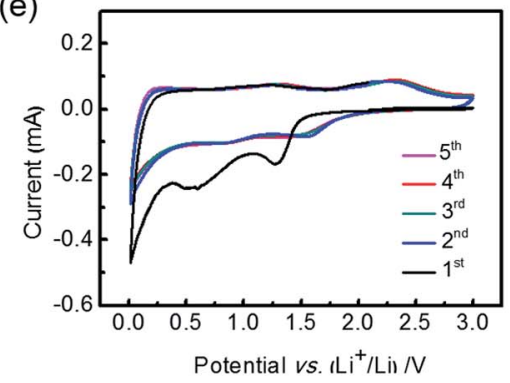

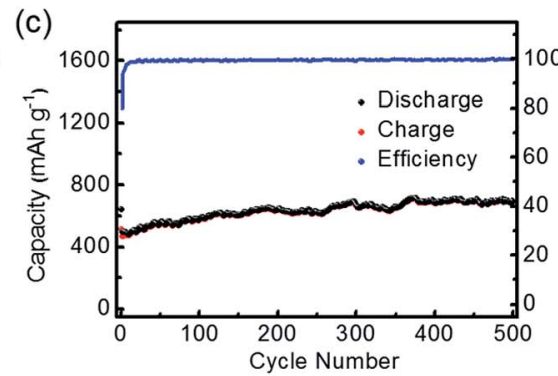

(f)

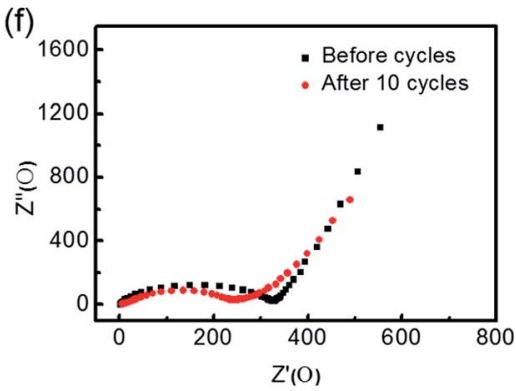

Fig. 6 (a) $1^{\text {st }}, 2^{\text {nd }}$ and $3^{\text {rd }}$ charge/discharge curves of the layer-cake-like $\mathrm{CO}_{3} \mathrm{O}_{4} / \mathrm{C}$ at a current density of $100 \mathrm{~mA} \mathrm{~g}^{-1}$. (b and c) $\mathrm{Charge} /$ discharge capacities vs. cycle numbers of the $\mathrm{CO}_{3} \mathrm{O}_{4} / \mathrm{C}$ at a current density of 100 and $500 \mathrm{~mA} \mathrm{~g}^{-1}$, respectively. (d) Discharge capacities vs. cycle numbers of the $\mathrm{CO}_{3} \mathrm{O}_{4} / \mathrm{C}$ at various current densities $\left(\mathrm{mA} \mathrm{g}^{-1}\right.$ ). (e) First 5 cycles of the $\mathrm{CV}$ curves for the $\mathrm{CO}_{3} \mathrm{O}_{4} / \mathrm{C}$ at a scan rate of $0.1 \mathrm{mV} \mathrm{s}{ }^{-1}$. (f) Impedance spectra of the $\mathrm{CO}_{3} \mathrm{O}_{4} / \mathrm{C}$ electrode before and after 10 cycles.

was increased to $500 \mathrm{~mA} \mathrm{~g}^{-1}$, the discharge capacity still maintained a high value of $692 \mathrm{~mA} \mathrm{~h} \mathrm{~g}^{-1}$ after long-term cycling (500 cycles), with a high and stable coulombic efficiency (Fig. 6c). Similarly, it was observed to show excellent stability of electrode capacity retention after a gradually rising stage. The phenomenon of an initial stage of rising capacity, which is welldocumented in other studies, ${ }^{33,39,40,44}$ was mainly due to the electrode activation effect, which is intrinsic to the conversion mechanism of TMO-based anodes, as well as the extra interfacial Li storage and reversible decomposition of the electrolyte. ${ }^{45}$ The desirable cycle stability can be mainly attributed to the unique nano-micro hierarchical structure, which simultaneously avoided the formation of a too-large electrode/ electrolyte interface, facilitated the diffusion of $\mathrm{Li}^{+}$and electrons, and resisted the volume expansion during cycles. In addition, the carbon coating treatment efficiently enhanced the electrode capacity retention through preventing the $\mathrm{Co}_{3} \mathrm{O}_{4}$ from directly contacting the electrolyte, and also resulted in better conductivity. Therefore, the advantage of the layer-cake-like $\mathrm{Co}_{3} \mathrm{O}_{4} / \mathrm{C}$ is most evident in its higher rate and longer-term cycling stability.

As shown in Fig. 6d, the discharge capacities at various current densities (between 100 and $1500 \mathrm{~mA} \mathrm{~g}^{-1}$ ) were further compared. The reversible capacity decreased monotonically as the rate increased. In particular, when tested at a high current density of $1500 \mathrm{~mA} \mathrm{~g}^{-1}$ it was able to deliver a discharge capacity of more than $420 \mathrm{~mA} \mathrm{~h} \mathrm{~g}^{-1}$. This meant that the discharge or charge process could be finished in about $16 \mathrm{~min}$, while a capacity above that of commercial graphite was achieved. It was also found that the capacity at high rate reached more than two thirds of the initial capacity at low rate, indicating the superior rate capability. Moreover, the capacity recovered to more than $700 \mathrm{~mA} \mathrm{~h} \mathrm{~g}^{-1}$ when the rate returned to $100 \mathrm{~mA} \mathrm{~g}^{-1}$ after cycling at a high rate, further corroborating the excellent rate capability and capacity retention of the layer-cake structure. In addition, the used $\mathrm{Co}_{3} \mathrm{O}_{4} / \mathrm{C}$ electrode was characterized by SEM, revealing that its morphology and structure were well preserved after 500 cycles (Fig. S7†). This is because the nanomicro hierarchical architecture could effectively buffer the volume variation during the cycles, and the carbon coating layer helped to stabilize the inner $\mathrm{Co}_{3} \mathrm{O}_{4}$.

To investigate the electrochemical reactions during the $\mathrm{Li}^{+}$ insertion/deinsertion processes more explicitly, cyclic voltammetry (CV) curves of the electrode made from $\mathrm{Co}_{3} \mathrm{O}_{4} / \mathrm{C}$ were carried out in the potential range of $3.0-0.01 \mathrm{~V} v s . \mathrm{Li} / \mathrm{Li}^{+}$at a scan rate of $0.1 \mathrm{mV} \mathrm{s}^{-1}$ (Fig. 6e). There were obvious peaks at $0.5-0.6 \mathrm{~V}$ and $1.2 \mathrm{~V}$ in the first cathodic scan, which were attributed to electrolyte decomposition and formation of an SEI layer. ${ }^{46} \mathrm{After}$ the first scan, cathodic peaks at $\sim 0.9 \mathrm{~V}$ and $\sim 1.4 \mathrm{~V}$ and corresponding anodic peaks at $\sim 1.3 \mathrm{~V}$ and $\sim 2.2 \mathrm{~V}$ were observed. The reduction/oxidation reaction of $\mathrm{Co}^{2+/ 3+} / \mathrm{Co}^{0}$ is a complex multistep process, because $\mathrm{Co}^{2+}$ and $\mathrm{Co}^{3+}$ ions occupy tetrahedral interstices and octahedral sites, respectively, of the cubic closely packed lattice of oxide anions in the spinel structure of $\mathrm{Co}_{3} \mathrm{O}_{4}{ }^{27}$ In extended scans the peaks exhibited similar densities, indicating the excellent electrochemical stability of the $\mathrm{Co}_{3} \mathrm{O}_{4} / \mathrm{C}$ anode. The cathodic peaks below $0.1 \mathrm{~V}$ could be assigned to the lithiation of carbon. ${ }^{47}$ The Nyquist impedance plots of the electrodes before and after cycling are compared in Fig. 6f, wherein the depressed semicircles at high frequency and inclined lines at low frequency correspond to charge impedance and lithium diffusion impedance, respectively. ${ }^{48}$ It exhibited obviously decreased impedance values after the initial 10 cycles, which was 
attributed to the electrode activation, electrolyte immersion, and opening of $\mathrm{Li}^{+}$diffusion channels. ${ }^{20}$

\section{Discussion on structure and performance}

Overall, it was observed that the $\mathrm{Co}_{3} \mathrm{O}_{4}$ exhibited excellent Listorage performance during long-term and high-rate cycling, accompanied by a high tap density. The performance of the layercake-like $\mathrm{Co}_{3} \mathrm{O}_{4} / \mathrm{C}$ with nano-micro hierarchical structures can be attributed to the synergistic effect of several factors: (1) $\mathrm{Co}_{3} \mathrm{O}_{4}$ served as a high capacity Li-storage framework due to its conversion mechanism when compared with traditional intercalation-mechanism anodes, accompanied by extra interfacial lithium storage, which further enhanced the system energy density. ${ }^{14,31}(2)$ The microsized overall dimensions of the $\mathrm{Co}_{3} \mathrm{O}_{4} / \mathrm{C}$ avoided the formation of a too-large electrode/electrolyte contact interface, which controlled the excess formation of SEI and thus alleviated the $\mathrm{Li}^{+}$consumption and capacity fade. ${ }^{6}$ Meanwhile, it guaranteed dense packing of particles, which gave rise to higher tap density than classical nanostructures such as the radial pompon-like structure. (3) The nanosized sheet-shaped building units and porous nature provided easier access and shortened diffusion paths for both $\mathrm{Li}^{+}$and electrons, thus benefiting the rate capability. Moreover, there was sufficient free space to efficiently buffer the volume variation during $\mathrm{Li}^{+}$insertion/deinsertion..$^{15}$ (4) The carbon coating layer prevented direct contact between the inner $\mathrm{Co}_{3} \mathrm{O}_{4}$ and the electrolyte, working as an artificial SEI layer to avoid excessive consumption of $\mathrm{Li}^{+}$and active material. It also helped to complement the low conductivity and resist the volume variation of the inner metal oxide. ${ }^{20,49}$

\section{Conclusions}

In this work, we have synthesized layer-cake-like $\mathrm{Co}_{3} \mathrm{O}_{4} / \mathrm{C}$ with a nano-micro hierarchical structure via a facile process, for high performance Li-storage applications. Its microsized overall dimensions gave rise to a high apparent tap density, which was more than 3 times that of the classical pompon-like structure, while avoiding a too-large electrode/electrolyte contact interface to alleviate the capacity fade. Meanwhile, its nanosized sheetshaped building units and porous nature provided easy access and shortened diffusion paths for both $\mathrm{Li}^{+}$and electrons, and sufficient free space to buffer the volume variation during cycles. Benefiting from multiple factors, the $\mathrm{Co}_{3} \mathrm{O}_{4} / \mathrm{C}$ exhibited an excellent reversible capacity and cycle stability. With a current density of $100 \mathrm{~mA} \mathrm{~g}^{-1}$ it reached a capacity as high as $739 \mathrm{~mA} \mathrm{~h} \mathrm{~g}^{-1}$, while being able to stabilize around $690 \mathrm{~mA} \mathrm{~h} \mathrm{~g}^{-1}$ at a high rate of $500 \mathrm{~mA} \mathrm{~g}^{-1}$ during long-term cycling (500 cycles). We anticipate that this work may provide new ideas for the production of TMO-based LIB anodes with long-term cycle stability and high tap density.

\section{Acknowledgements}

This work was supported by National Natural Science Foundation of China (Nos 21503006, 21276257, 91534109 and 11574262), the "Strategic Priority Research Program" of the Chinese Academy of
Sciences (No. XDA09010103) and National Key Projects for Fundamental Research and Development of China (No. 2016YFB0100104).

\section{References}

1 M. N. Obrovac and V. L. Chevrier, Chem. Rev., 2014, 114, 11444-11502.

2 N. W. Li, Y. X. Yin, C. P. Yang and Y. G. Guo, Adv. Mater., 2016, 28, 1853-1858.

3 X. B. Cheng, T. Z. Hou, R. Zhang, H. J. Peng, C. Z. Zhao, J. Q. Huang and Q. Zhang, Adv. Mater., 2016, 28, 2888-2895.

4 Y. X. Tang, Y. Y. Zhang, W. L. Li, B. Ma and X. D. Chen, Chem. Soc. Rev., 2015, 44, 5926-5940.

5 X. J. Wang, J. Feng, Y. C. Bai, Q. Zhang and Y. D. Yin, Chem. Rev., 2016, 116, 10983-11060.

6 N. Liu, Z. D. Lu, J. Zhao, M. T. McDowell, H. W. Lee, W. T. Zhao and Y. Cui, Nat. Nanotechnol., 2014, 9, 187-192.

7 D. C. Lin, Z. D. Lu, P. C. Hsu, H. R. Lee, N. Liu, J. Zhao, H. T. Wang, C. Liu and Y. Cui, Energy Environ. Sci., 2015, 8, 2371-2376.

8 Q. Xu, J. Y. Li, J. K. Sun, Y. X. Yin, L. J. Wan and Y. G. Guo, Adv. Energy Mater., 2017, 7, 1601481.

9 S. Chae, M. Ko, S. Park, N. Kim, J. Ma and J. Cho, Energy Environ. Sci., 2016, 9, 1251-1257.

10 J. Ryu, D. Hong, M. Shin and S. Park, ACS Nano, 2016, 10, 10589-10597.

11 Y. H. Zou, S. Chen, X. F. Yang, N. Ma, Y. Z. Xia, D. J. Yang and S. J. Guo, Adv. Energy Mater., 2016, 6, 1601549.

12 G. L. Hou, B. L. Chen, Y. B. Cao, M. S. Yao, B. Q. Li, C. Zhang, Q. H. Weng, X. Wang, Y. Bando, D. Golberg and F. L. Yuan, Nano Energy, 2016, 24, 111-120.

13 Y. P. Zhu, T. Y. Ma, M. Jaroniec and S. Z. Qiao, Angew. Chem., Int. Ed., 2017, 56, 1324-1328.

14 V. Aravindan, Y. S. Lee and S. Madhavi, Adv. Energy Mater., 2015, 5, 1402225.

15 J. Yu, S. M. Chen, W. J. Hao and S. J. Zhang, ACS Nano, 2016, 10, 2500-2508.

16 X. Ge, C. D. Gu, X. L. Wang and J. P. Tu, J. Phys. Chem. C, 2014, 118, 911-923.

17 Y. Wang and G. Z. Cao, Adv. Mater., 2008, 20, 2251-2269.

18 X. H. Xia, J. P. Tu, Y. Q. Zhang, X. L. Wang, C. D. Gu, X. B. Zhao and H. J. Fan, ACS Nano, 2012, 6, 5531-5538.

19 H. J. Qiu, L. Liu, Y. P. Mu, H. J. Zhang and Y. Wang, Nano Res., 2015, 8, 321-339.

20 J. Yu, X. Wang, S. M. Chen, X. Y. Liu and S. J. Zhang, Nano Res., 2017, 10, 172-186.

21 H. Zhang, Y. Lu, C. D. Gu, J. B. Cai, X. L. Wang and J. P. Tu, Electrochim. Acta, 2013, 118, 472-479.

22 W. M. Mei, J. Huang, L. P. Zhu, Z. Z. Ye, Y. J. Mai and J. P. Tu, J. Mater. Chem., 2012, 22, 9315-9321.

23 L. P. Zhu, Z. Wen, W. M. Mei, Y. G. Li and Z. Z. Ye, J. Phys. Chem. C, 2013, 117, 20465-20473.

24 L. Li, K. H. Seng, Z. X. Chen, Z. P. Guo and H. K. Liu, Nanoscale, 2013, 5, 1922-1928.

25 N. Jayaprakash, W. D. Jones, S. S. Moganty and L. A. Archer, J. Power Sources, 2012, 200, 53-58. 
26 X. W. Lou, D. Deng, J. Y. Lee and L. A. Archer, Chem. Mater., 2008, 20, 6562-6566.

27 W. Y. Li, L. N. Xu and J. Chen, Adv. Funct. Mater., 2005, 15, 851-857.

28 Y. C. Jiao, D. D. Han, L. M. Liu, L. Ji, G. N. Guo, J. H. Hu, D. Yang and A. G. Dong, Angew. Chem., Int. Ed., 2015, 54, 5727-5731.

29 S. L. Xiong, J. S. Chen, X. W. Lou and H. C. Zeng, Adv. Funct. Mater., 2012, 22, 861-871.

30 W. J. Hao, S. M. Chen, Y. J. Cai, L. Zhang, Z. X. Li and S. J. Zhang, J. Mater. Chem. A, 2014, 2, 13801-13804.

31 Y. F. Zhukovskii, P. Balaya, E. A. Kotomin and J. Maier, Phys. Rev. Lett., 2006, 96, 058302.

32 D. Q. Liu, X. Wang, X. B. Wang, W. Tian, Y. Bando and D. Golberg, Sci. Rep., 2013, 3, 2543.

33 X. L. Xiao, X. F. Liu, H. Zhao, D. F. Chen, F. Z. Liu, J. H. Xiang, Z. B. Hu and Y. D. Li, Adv. Mater., 2012, 24, 5762-5766.

34 J. S. Cho, Y. J. Hong and Y. C. Kang, ACS Nano, 2015, 9, 40264035.

35 Y. Wang, H. Xia and J. Y Lin, ACS Nano, 2010, 4, 1425-1432.

36 C. C. Li, X. M. Yin, T. H. Wang and H. C. Zeng, Chem. Mater., 2009, 21, 4984-4992.

37 K. X. Yao and H. C. Zeng, J. Phys. Chem. C, 2009, 113, 13731385.

38 A. K. Rai, L. T. Anh, J. Gim and J. Kim, Ceram. Int., 2013, 39, 9325-9330.
39 D. D. Li, L. X. Ding, S. Q. Wang, D. D. Cai and H. H. Wang, J. Mater. Chem. A, 2014, 2, 5625-5630.

40 P. Poizot, S. Laruelle, S. Grugeon, L. Dupont and J. Tarascon, Nature, 2000, 407, 496-499.

41 M. E. Im, D. Pham-Cong, J. Y. Kim, H. S. Choi, J. H. Kim, J. P. Kim, J. Kim, S. Y. Jeong and C. R. Cho, J. Power Sources, 2015, 284, 392-399.

42 Y. S. Hu, R. Demir-Cakan, M. M. Titirici, J. O. Muller, R. Schlogl, M. Antonietti and J. Maier, Angew. Chem., Int. Ed., 2008, 47, 1645-1649.

43 M. V. Reddy, T. Yu, C. H. Sow, Z. X. Shen, C. T. Lim, G. V. S. Rao and B. V. R. Chowdari, Adv. Funct. Mater., 2007, 17, 2792-2799.

44 Y. G. Li, B. Tan and Y. Y. Wu, Nano Lett., 2008, 8, 265-270. 45 C. Peng, B. Chen, Y. Qin, S. Yang, C. Li, Y. Zuo, S. Liu and J. Yang, ACS Nano, 2012, 6, 1074-1081.

46 R. Z. Yang, Z. X. Wang, J. Y. Liu and L. Q. Chen, Electrochem. Solid-State Lett., 2004, 7, A496-A499.

47 L. Yang, S. Cheng, Y. Ding, X. B. Zhu, Z. L. Wang and M. L. Liu, Nano Lett., 2012, 12, 321-325.

48 W. W. Li, S. M. Chen, J. Yu, D. L. Fang, B. Z. Ren and S. J. Zhang, Green Energy \& Environment, 2016, 1, 91-99.

49 J. Liu, P. Kopold, P. A. van Aken, J. Maier and Y. Yu, Angew. Chem., Int. Ed., 2015, 54, 9632-9636. 